\title{
PCR evaluation of false-positive signals from two automated blood-culture systems
}

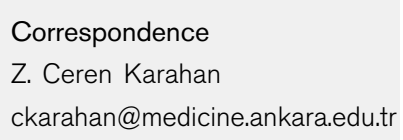

Received 9 June 2005

Accepted 21 September 2005

\author{
Z. Ceren Karahan, ${ }^{1}$ Ipek Mumcuoglu, ${ }^{2}$ Haluk Guriz, ${ }^{3}$ Deniz Tamer, ${ }^{1}$ \\ Neriman Balaban, ${ }^{2}$ Derya Aysev ${ }^{3}$ and Nejat Akar ${ }^{1}$ \\ ${ }^{1,3}$ Division of Paediatric Molecular Pathology and Genetics ${ }^{1}$ and Cebeci Hospital Central \\ Microbiology Laboratory ${ }^{3}$, Ankara University, School of Medicine, 06100-Cebeci, Ankara, \\ Turkey \\ ${ }^{2}$ Microbiology and Clinical Microbiology Department, Ankara Numune Education and \\ Investigation Hospital, 06100-Sihhiye, Ankara, Turkey
}

\section{INTRODUCTION}

Bloodstream infections are the most important causes of morbidity and mortality in hospital settings. Rapid and reliable detection of micro-organisms from blood is one of the most critical functions of a diagnostic microbiology laboratory. Automated blood-culture systems with continuous monitoring not only reduce the time needed to detect positive cultures, but also decrease specimen handling. Two such systems, the BACTEC 9000 series (Becton Dickinson) and the BacT/Alert (Biomérieux) are widely used. Both systems are fully automated, and monitor the growth of organisms by measuring the production of $\mathrm{CO}_{2}$ with a colorimetric (BacT/Alert) or fluorescent (BACTEC) sensor. The main advantages of these systems over conventional blood-culture methods are full automation, a shorter time

Abbreviations: ANEIH, Ankara Numune Education and Investigation Hospital; AUSM-CH, Ankara University School of Medicine-Cebeci Hospital. to detect pathogens, considerable labour savings and improved laboratory work flow (Ziegler et al., 1998). Both systems offer specific aerobic and anaerobic media which remove growth inhibitors from patient blood to enhance the recovery of fastidious organisms and improve the detection of bacteraemia and fungaemia in patients receiving antimicrobial therapy. BACTEC Plus/F medium contains soybean-casein digest broth, primary supplements, a nonionic absorbing resin and a cation-exchange resin. BacT/ Alert FAN medium has a brain heart infusion broth base containing Ecosorb, which contains adsorbent charcoal, fuller's earth, and other components (Saito et al., 2004; Ziegler et al., 1998).

Various studies have shown that for about $1-10 \%$ of the samples processed by these automated systems that give a positive result, subsequent Gram stain and subculture on standard media yield no bacteria (Cockerill et al., 1997; Qian et al., 2001; Ziegler et al., 1998). False-positive results lead to uncertainty about whether they are the result of the 
growth of fastidious organisms that are not cultivable on standard media or whether they are true instrument false positives' (Daxboeck et al., 2004). From this point of view, in this study, we aimed to investigate the presence of pathogens by eubacterial and fungal PCR in 'false-positive' bottles obtained from the BACTEC 9050 and BacT/Alert systems.

\section{METHODS}

Blood-culture bottles. A total of 169 subculture-negative aerobic blood-culture bottles obtained from different patients hospitalized in two different hospitals in Ankara, Turkey, were evaluated in this study. One hundred and four BacT/Alert blood-culture bottles were obtained from Ankara Numune Education and Investigation Hospital (ANEIH) and 65 BACTEC 9050 Aerobic Plus F bottles were obtained from Central Microbiology Laboratory of Ankara University School of Medicine-Cebeci Hospital (AUSM-CH).

From all patients, blood was drawn by doctors or nurses in the clinics after appropriate decontamination of the skin, and the blood-culture bottles were inoculated with $8-10 \mathrm{ml}$ blood. In both systems, the bottles were routinely incubated for 7 days before being unloaded from the system, unless a positive signal was obtained. At ANEIH, all the bottles which remained negative during this period were subjected to Gram stain, as well as terminal subculture on $5 \%$ blood agar and MacConkey agar for $48 \mathrm{~h}$ at $37^{\circ} \mathrm{C}$ under aerobic conditions. Terminal Gram staining and subculture were not performed at AUSM-CH. In both hospitals, positive bottles were unloaded from the system when a positive signal was obtained during working hours. For the bottles which gave positive signals at night (between 17:30 PM and 08:00 $\mathrm{AM}$ ), the bottles were unloaded from the system at 08:00 AM. The samples taken from the bottles were Gram stained, and also subcultured onto blood agar and MacConkey agar and incubated at $37^{\circ} \mathrm{C}$ for $24-48 \mathrm{~h}$ under aerobic conditions. At AUSM-CH, an additional subculture was performed on chocolate agar. Gram-stainnegative bottles were reloaded onto the system and incubated until subculture results were obtained. All the bottles included in this study were instrument-positive bottles which remained Gram-stain and subculture negative after this period. For patients with more than one instrument-positive, subculture-negative bottle, only one bottle was included in the study.

DNA extraction. The bottles were kept at $-20^{\circ} \mathrm{C}$ until the DNA extraction was performed. Bacterial and fungal DNA was extracted from the bottles by the alkali wash/lysis method described by Millar et al. (2000). Extracted DNA was stored at $-20^{\circ} \mathrm{C}$ prior to PCR.

Eubacterial 16S rDNA amplification. The oligonucleotide primers fD1 (5' AGAGTTTGATCCTGGCTCAG $\left.3^{\prime}\right)$ and 800R (5' GAGTACCAGGGTATCTAATCC $3^{\prime}$ ) were used to amplify an $800 \mathrm{bp}$ region of the gene encoding the $16 \mathrm{~S}$ rRNA of eubacteria. The PCR mixture contained $5 \mu$ l extracted bacterial DNA, 25 pmol of each primer, $200 \mu \mathrm{mol}$ each dNTP, $1.5 \mathrm{mM} \mathrm{MgCl}_{2}$ and $1.5 \mathrm{U}$ Taq DNA polymerase (Fermentas) in the appropriate $10 \times$ buffer in a total volume of $50 \mu \mathrm{l}$. PCR amplification included an initial denaturation for $5 \mathrm{~min}$ at $94^{\circ} \mathrm{C}$, followed by a total of 35 cycles consisting of a denaturation step at $94{ }^{\circ} \mathrm{C}$ for $1 \mathrm{~min}$, annealing at 60/58/ $55^{\circ} \mathrm{C}$ for $1 \mathrm{~min}(2 / 2 / 31 \mathrm{cycles})$, and elongation at $72^{\circ} \mathrm{C}$ for $1 \mathrm{~min}$. A final extension for 4 min was performed, and the products were subjected to $2 \%(\mathrm{w} / \mathrm{v})$ agarose gel electrophoresis. Bands were visualized under UV after ethidium bromide staining of the gel.

Fungal ITS region amplification. The oligonucleotide primers ITS-1 $\quad\left(5^{\prime}\right.$ TTCGTAGGTGAACCTGCGG $\left.3^{\prime}\right)$ and ITS-4 $\left(5^{\prime}\right.$
TCCTCCGCTTATTGATATGC $3^{\prime}$ ) were used to amplify an approximately $500 \mathrm{bp}$ fungal sequence, as described elsewhere (Velegraki et al., 1999).

In order to determine the efficiency of the extraction protocol and the PCR, DNA extracted from an additional four sets of bottles was used to provide positive and negative controls for each system. These four sets included three uninoculated bottles, three instrument true-negative bottles, three instrument true-positive bottles (one Candida albicans, one Staphylococcus aureus and one Escherichia coli), and three aerobic bottles artificially inoculated with C. albicans, S. aureus and E. coli. Both eubacterial and fungal PCR had previously been performed with bacterial and fungal DNA extracted directly from the culture material, and the results obtained by automated DNA sequencing correlated well with the PCR results (data not shown). For each PCR performed, one culture-extracted DNA sample was also used as an internal control for the amplification reaction.

All the reactions were performed twice, and PCR of the negative samples was repeated once after the addition of $0.5 \%$ BSA to the reaction mixture to eliminate the possibility of PCR inhibition, as suggested by Qian et al. (2001).

165 rDNA sequencing. In order to identify the amplicons observed in the $16 \mathrm{~S}$ rDNA amplification, the products were purified by the EZNA Cycle-Pure Kit (Omega Bio-tek), according to the manufacturer's instructions, and subjected to automated sequencing with a CEQ2000XL sequencer (Beckman Coulter) by using the fD1 and 610R (5' TACCGCGGCTGCTGGCAC 3') primers. The nucleotide sequences of these amplicons were matched to existing GenBank sequences by nucleotide-nucleotide BLAST analysis.

\section{RESULTS}

All 169 bottles (104 BacT/Alert and 65 BACTEC) from different patients were evaluated by eubacterial and fungal PCR. PCR of the uninoculated and instrument true-negative bottles were negative, and instrument true-positive and artificially inoculated bottles gave positive results. For each PCR amplification, the internal control was also positive. None of the patient bottles gave positive results by fungal PCR. Eubacterial PCR yielded 10 positive results in BacT/ Alert bottles $(10 / 104=9 \cdot 6 \%)$, while all of the BACTEC bottles were negative.

The BacT/Alert bottles were obtained from patients hospitalized in various ANEIH clinics between December 2003 and April 2004. During this period, a total of 11027 bottles from 6372 patients were sent to the laboratory. Of these bottles, $8743(79 \cdot 3 \%)$, belonging to 3044 different patients, gave positive signals. One hundred and twenty-one ( $1.4 \%$ of positive bottles; $1 \%$ of all bottles) of these positive signals obtained from the bottles of 104 different patients were false positives. Of these 104 bottles, $10(9 \cdot 6 \%)$ were found to contain microbial sequences by eubacterial PCR. These PCR-positive bottles were obtained from 10 different patients (eight male and two female, aged between 43 and 71 years, with a mean of 56.7 years). Among these 10 patients, a set of three bottles was sent from two patients, and a set of two bottles was sent from one patient. For the remaining seven patients, only one bottle was sent to the laboratory. These bottles gave positive signals between 2 and 5 days of incubation (mean $3 \cdot 5$ days). Sequence-analysis 
results of the positive PCR amplicons were as follows: one P. multocida, two Staphylococcus epidermidis, one Staphylococcus hominis, one Micrococcus sp., one Strep. pneumoniae, two Corynebacterium spp., one Brachibacterium sp. and one Arthrobacter/Rothia sp. The characteristics of the patients and the micro-organisms detected are shown in Table 1.

No additional blood cultures were sent to the microbiology laboratory for these patients. For patient 1 , abcess drainage material was also sent to the microbiology laboratory, which yielded no bacterial growth. During hospitalization, patient 10 developed aspiration pneumonia and sputum culture was carried out. A sputum culture was also obtained from patient 2, who was hospitalized with a diagnosis of pneumonia, but in both sputum cultures, only normal flora were observed. For patient 6 , an additional urine culture was made, and $10^{5}$ c.f.u. E. coli $\mathrm{ml}^{-1}$ was detected.

\section{DISCUSSION}

All the bottles evaluated in this study were found to be negative for fungi by PCR. For the BACTEC system, eubacterial PCR of all the bottles was also negative. For this reason, all 'false positive' bottles obtained from this system were regarded as 'true instrument false positive'. The falsepositive rate of this system has been reported to be 0.3-10.4\% (Cockerill et al., 1997; Daxboeck et al., 2004; Durmaz et al., 2003; Nolte et al., 1993; Qian et al., 2001; Smith et al., 1995; Ziegler et al., 1998). At AUSM-CH, about $1 \%$ of the BACTEC bottles were found to be false positive. Daxboeck et al. (2004) also failed to detect any bacterial or fungal DNA in this system by PCR. False positives in this system may be due to the elevated leukocyte counts of the patients (Daxboeck et al., 2004) or the high sensitivity of the system in detecting the background increases in $\mathrm{CO}_{2}$ concentration which may be produced by blood cells (Nolte et al., 1993).

In 10 patients, the blood-culture bottles loaded to the BacT/ Alert system were found to contain microbial DNA by eubacterial PCR. The false-positive rate of this system was $1 \%$ at ANEIH, which is comparable with previous reports (Ziegler et al., 1998). Most of the identified bacteria (Staphylococcus spp., Corynebacterium spp., Micrococcus spp., Brachibacterium spp. and Rothia spp.) were members of the skin flora, and except for the S. epidermidis isolate of patient 9, all were obtained from one bottle. Patient 9 was hospitalized in the nephrology department with a diagnosis of chronic renal failure. From this patient, a set of three

Table 1. Characteristics of the patients, and micro-organisms detected

Abbreviations: M, male; F, female; ALL, acute lymphocytic leukaemia; AML, acute myelocytic leukaemia.

\begin{tabular}{|c|c|c|c|c|c|c|c|c|}
\hline $\begin{array}{l}\text { Patient } \\
\text { no. }\end{array}$ & & $\begin{array}{c}\text { Age } \\
\text { (years) }\end{array}$ & $\begin{array}{l}\text { Underlying } \\
\text { disease }\end{array}$ & $\begin{array}{l}\text { Antibiotic } \\
\text { usage }\end{array}$ & Clinic & $\begin{array}{l}\text { No. of } \\
\text { false- } \\
\text { positive } \\
\text { bottles }\end{array}$ & $\begin{array}{c}\text { Day } \\
\text { positive }\end{array}$ & $\begin{array}{c}\text { Micro-organism detected } \\
(\% \text { match with } \\
\text { GenBank sequence })\end{array}$ \\
\hline 1 & M & 61 & $\begin{array}{l}\text { Hepatopleurobronchial } \\
\text { fistula }\end{array}$ & - & Surgery & 2 & 3 & $\begin{array}{l}\text { Pasteurella multocida subsp. } \\
\text { septica }(100 \%)\end{array}$ \\
\hline 2 & $\mathrm{M}$ & 60 & Pneumonia & - & Emergency & 3 & 3 & Streptococcus pneumoniae (100\%) \\
\hline 3 & M & 43 & ALL (exitus) & $\begin{array}{l}\text { Trimethoprim/ } \\
\text { sulfamethoxazole }^{\star}\end{array}$ & Oncology & 1 & 4 & Micrococcus spp. (99\%) \\
\hline 4 & M & 47 & Pulmonary cancer & - & Oncology & 1 & 5 & Corynebacterium sp. (99\%) \\
\hline 5 & $\mathrm{~F}$ & 59 & AML & $\begin{array}{l}\text { Ornidazole }+ \\
\text { piperacillin/ } \\
\text { tazobactam }^{\star}\end{array}$ & Haematology & 1 & 4 & Corynebacterium sp. (100\%) \\
\hline 6 & M & 58 & AML & - & Haematology & 1 & 4 & $\begin{array}{l}\text { Rothia/Arthrobacter/Actinomyces } \\
\text { sp. }(100 \%)\end{array}$ \\
\hline 7 & M & 57 & ALL & $\begin{array}{l}\text { Amoxycillin/ } \\
\text { clavulanate }^{*}\end{array}$ & $\begin{array}{l}\text { Bone marrow } \\
\text { transplantation }\end{array}$ & 1 & 3 & Brachibacterium sp. (100\%) \\
\hline 8 & $\mathrm{~F}$ & 71 & $\begin{array}{l}\text { Chronic obstructive } \\
\text { pulmonary disease }+ \\
\text { congestive heart } \\
\text { failure (exitus) }\end{array}$ & - & Infectious diseases & 1 & 4 & Staphylococcus hominis (96\%) \\
\hline 9 & M & 46 & Chronic renal failure & - & Nephrology & 3 & 3 & Staphylococcus epidermidis (98\%) \\
\hline 10 & M & 65 & $\begin{array}{l}\text { Cerebrovascular } \\
\text { occlusion (exitus) }\end{array}$ & - & Neurology & 1 & 2 & Staphylococcus epidermidis (100\%) \\
\hline
\end{tabular}

${ }^{\star}$ These patients were under antibiotic therapy when the blood cultures were taken. 
bottles was sent to the laboratory, and all of them were designated 'false positive'. When the characteristics of the patient and the total number of positive bottles were taken into account, the isolate was considered as the probable aetiological agent. Single culture of Corynebacterium spp., coagulase-negative staphylococci, viridans group streptococci, Neisseria spp. other than Neisseria gonorrhoeae and Neisseria meningitidis, Bacillus spp. and Micrococcus spp. can be assumed to be due to contamination, since these are constituents of the skin flora (Durmaz et al., 2003). As these bacteria normally grow on laboratory media, their inability to grow on subculture may be due to the antibiotic usage of the patients and conversion of these organisms to $L$ forms. Our routine subculture conditions were inadequate for growth of damaged or defective organisms.

Another explanation of our inability to grow these bacteria on subcultures could be that the blood-culture bottles contained DNA fragments incorporated during the manufacturing process, but not those of an infecting organism. The uninoculated blood-culture media of both of the commercial blood-culture systems examined in this study were shown to contain contaminating bacterial sequences: the uninoculated aerobic and anaerobic BACTEC bloodculture media were shown to contain 16SrRNA genes from the Bacillus genus, whereas the BacT/Alert aerobic and anaerobic blood-culture media contained genes related to the Streptococcus genus, with the closest phylogenetic neighbours being Streptococcus mitis, Strep. pneumoniae and Streptococcus oralis. This showed that these media are not free of microbial DNA (Fredricks \& Relman, 1998). Although only three uninoculated bottles were evaluated by PCR for each system, we did not observe any amplicon from these bottles, suggesting that our results were not due to the presence of amplicons in the culture prior to inoculation.

The presence of a streptococcal sequence related to Strep. pneumoniae in BacT/Alert blood-culture media is particularly disturbing, since we detected a Strep. pneumoniae sequence in one patient (patient 1). This patient was admitted to the Emergency Department of the hospital with a diagnosis of pneumonia, and a set of three bottles gave positive signals. Strep. pneumoniae may lyse in blood-culture bottles, and subcultures may remain negative, despite heavy bacterial growth (Daxboeck et al., 2004). When the characteristics of the patient and our inability to show any contaminating amplicon in the uninoculated bottles are taken into account, the sequence obtained from the bottles of this patient is considered to be due to the real aetiological agent.

The sequence of $P$. multocida subsp. septica was obtained from a patient (patient 2) with two 'false-positive' bottles. The patient had undergone surgery because of a hepatopleurobronchial fistula. This sequence was also assigned to the aetiological agent of the patient. Since culture of abcess drainage material from this patient obtained afterwards revealed no bacterial growth, our inability to grow the organism on subculture may have been due to the antibiotic usage of this patient.
As a result, all of the 'false positive' signals of the BACTEC system were regarded as 'instrument true false positives', as none of these bottles gave positive results by eubacterial and fungal PCR. For the BacT/Alert system, about $11 \%$ of the false-positive bottles were found by eubacterial PCR to contain bacterial DNA. Most of these sequences ( $80 \%)$ belonged to members of the skin flora, and could be considered to be contamination. In two patients (patients 1 and 2), DNA sequences of true aetiological agents (one Strep. pneumoniae and one P. multocida subsp. septica) were obtained. From one patient (patient 9), a probable aetiological agent ( $S$. epidermidis) was determined. Antibiotic usage of the patient may be responsible for the inability of the laboratory to grow these bacteria on subculture. For patients with more than one false-positive bottle, molecular methods can be used to evaluate the microbial DNA in these bottles, but the financial burden of the test must also be taken into account, as it may not be acceptable to maintain the PCR assay, especially when the number of such cultures is very low. For patients with only one positive bottle, using molecular methods increases the labour costs, and we recommend not to evaluate these bottles further. For these patients, additional blood cultures can be performed when the patient is not receiving antibiotic treatment, and additional subcultures can be performed on hypertonic media for the recovery of cellwall-deficient bacteria and on anaerobic media for the recovery of anaerobic organisms, if suspected.

\section{REFERENCES}

Cockerill, F. R., III, Reed, G. S., Hughes, J. G. \& 7 other authors (1997). Clinical comparison of BACTEC 9240 Plus Aerobic/F Resin Bottles and the Isolator Aerobic Culture System for detection of bloodstream infections. J Clin Microbiol 35, 1469-1472.

Daxboeck, F., Dornbusch, H. J., Krause, R., Assadian, O. \& Wenisch, C. (2004). Verification of false-positive blood culture results generated by the BACTEC 9000 series by eubacterial $16 \mathrm{~S}$ rDNA and panfungal $18 \mathrm{~S}$ rDNA directed polymerase chain reaction (PCR). Diagn Microbiol Infect Dis 48, 1-3.

Durmaz, G., Us, T., Aydinli, A., Kiremitci, A., Kiraz, N. \& Akgün, Y. (2003). Optimum detection times for bacteria and yeast species with the BACTEC 9120 aerobic blood culture system: evaluation for a 5 -year period in a Turkish university hospital. J Clin Microbiol 41, 819-821.

Fredricks, D. N. \& Relman, D. A. (1998). Improved amplification of microbial DNA from blood cultures by removal of the PCR inhibitor sodium polyanetholsulfonate. $J$ Clin Microbiol 36, 2810-2816.

Millar, B. C., Jiru, X., Moore, J. E. \& Earle, J. A. P. (2000). A simple and sensitive method to extract bacterial, yeast and fungal DNA from blood culture material. J Microbiol Methods 42, 139-147.

Nolte, F. S., Williams, J. M., Jerris, R. C., Morello, J. A., Leitch, C. D., Matushek, S., Schwabe, L. D., Dorigan, F. \& Kocka, F. E. (1993). Multicenter clinical evaluation of continuous monitoring blood culture system using fluorescent-sensor technology (BACTEC 9240). J Clin Microbiol 31, 552-557.

Qian, Q., Tang, Y.-W., Kolbert, C. P. \& 7 other authors (2001). Direct identification of bacteria from positive blood cultures by 
amplification and sequencing of the 16SrRNA gene: evaluation of BACTEC 9240 instrument true-positive and false-positive results. J Clin Microbiol 39, 3578-3582.

Saito, T., linuma, Y., Takakura, S., Fujihara, N., Kudo, T. \& Ichiyama, S. (2004). Can BacT/Alert FA and FN blood culture bottles increase the recovery of microorganisms in the clinical laboratory? J Chemother 10, 343-347.

Smith, J. A., Bryce, E. A., Ngui-Yen, J. H. \& Roberts, F. J. (1995). Comparison of BACTEC 9240 and BacT/Alert blood culture systems in an adult hospital. J Clin Microbiol 33, 1905-1908.
Velegraki, A., Manousos, E. K., Skiniotis, G., Savala, M., MitroussiaZiouva, A. \& Legakis, N. J. (1999). Identification of medically significant fungal genera by polymerase chain reaction followed by restriction enzyme analysis. FEMS Immunol Med Microbiol 23, 303-312.

Ziegler, R., Johnscher, I., Martus, P., Lenhardt, D. \& Just, H. M. (1998). Controlled clinical laboratory comparison of two supplemented aerobic and anaerobic media used in automated blood culture systems to detect bloodstream infections. J Clin Microbiol 36, 657-661. 